\title{
Regras de reconhecimento e a legitimidade da decisão jurídica em Hart
}

\author{
Rules of recognition and legitimacy of the judicial decision in Hart
}

\author{
Rafael Lazzarotto Simioni \\ Rodrigo Pedroso Barbosa
}

\section{Resumo}

A proposta do trabalho reside em explorar o conceito da legitimidade no marco teórico de Herbert Lionel Adolphus Hart. A questão da legitimidade está na base do Estado Democrático de Direito e do convívio social, sendo ao mesmo tempo questão complexa e de suma importância, abordada em diversas hipóteses e teorias, mas sem nunca uma resposta definitiva. Observa-se inicialmente a própria necessidade de fundamentação da legitimidade e sua relaçáo com o conceito de justiça. Prossegue-se analisando a visão de Hart sobre regras primárias e secundárias, e o papel das regras de reconhecimento como fator de legitimidade do ordenamento jurídico. Por último, estuda-se a questáo da derrotabilidade das regras jurídicas, fenômeno em que regras retiram a efetividade de outras, como é o caso do instituto da legítima defesa. Conclui-se que, apesar de não ser possível, ao menos no momento, encontrar uma resposta definitiva para a pergunta da legitimidade, Hart nos oferece uma visão sofisticada, baseada em fatos sociais, sem necessidade de construçóes hipotéticas, tornando possível identificar, através de regras de reconhecimento, a legitimidade embutida no sistema.

\section{Palavras-chave}

Legitimidade; Derrotabilidade; Filosofia do Direito.

\begin{abstract}
The proposal for this article is to explore the concept of legitimacy, based on the theoretical framework advanced by Herbert Lionel Adolphus Hart. The question of legitimacy is located at the base of the Democratic State and social interactions, being, at the same time, a complex and extremely important question, approached by several hypothesis and theories, but never reaching a definitive answer. At first, it is observed the necessity of a basis of the legitimacy, and its relation with the concept of justice. This article proceeds to analyze Hart's vision about primary and secondary rules, and the role of the rules of recognition as a legitimation factor of the legal framework. Lastly, it studies the question of the defeasibility of the legal rules, a phenomenon where some rules take away the effectivity of others, as is the case with the self-defense institute. It is concluded that, although it is not possible, at least for the time being, to find a definitive answer to the question of legitimacy, Hart gives us a sophisticated view, based on social facts, without the need of hypothetical constructs, making it possible to identify, through rules of recognition, the legitimacy embedded in the system.
\end{abstract}

\section{Keywords}

Legitimacy; Defeasibility; Legal Philosophy. 


\section{Introdução}

A existência de comandos a serem seguidos (normas, regras) estáo na base de qualquer sociedade, desde as mais arcaicas às mais modernas. Sua presença é inquestionável. Porém, para estes comandos serem válidos, obrigatórios e coercitivos, eles devem ter como característica originária um quê que lhes concede uma qualidade especial, que chamamos legitimidade. Legitimidade é o que torna algo, norma, comando ou autoridade, legítimo, dotado desta característica de validade. No presente artigo busca-se analisar a questáo da legitimidade pela ótica de Herbert Lionel Adolphus Hart.

Busca-se, no presente artigo, compreender o fenômeno, ou característica, da legitimidade, inquerindo, antes de mais nada, a necessidade de que esta seja fundamentada. Em seguida, prossegue-se para um estudo detalhado e analítico da visão de Hart sobre regras e sua legitimidade, estendendo-se até mesmo à questão da legitimidade do poder do Estado. Por último, tendo-se compreendido a necessidade da fundamentação e a própria legitimidade, explora-se a construçáo do jusfilósofo acerca da "derrotabilidade", limites estabelecidos nas próprias regras para as regras.

$\mathrm{O}$ questionamento aqui feito não é sem propósito. O questionamento sobre a razão que certos comandos devem ser obrigatoriamente observados e a origem da autoridade é recorrente por toda a história da sociedade, com diversas hipóteses e teorias apresentadas, mas jamais totalmente respondido. Nem mesmo a visão de uma norma fundamental, apresentada por Hans Kelsen, é suficiente para solucionar tal dilema e, como aponta Hart, apresenta diversas falhas que a tornam não apenas insuficiente, mas inadequada. Assim, busca-se outra possível solução para esta questão essencial da legitimidade, que aflige e ao mesmo tempo reside nos fundamentos de um Estado Democrático de Direito. O presente artigo foi desenvolvido através da análise de doutrinas jurídicas e literatura extrajurídica, com marco teórico na obra de Herbert Lionel Adolphus Hart.

\section{Justição e a necessidade de um fundamento da legitimidade}

Talvez uma das perguntas mais importantes no contexto jurídico é o porquê de se dever obedecer a lei. Tal pergunta é apresentada em diversos contextos, ora em defesa da lei e do Estado, ora com um viés anarquista ou, ao menos, libertário, no sentido de que leis tem como principal funçáo cercear a liberdade inata de todos os seres humanos. Está é uma visão essencialmente liberal, ou o Estado GuardaNoturno, de Lassale (CANOTILHO, 2003). Porém, por menor que seja o número de leis existentes, algumas existirão, e estas devem ser obedecidas, caso se busque uma 
vida em sociedade com justiça. Cabe, então, o questionamento de quais leis devem ser obedecidas. Ou seja, quais estáo dotadas de legitimidade.

Afinal, como pergunta Miguel Reale, porque devemos obedecer à lei, sacrificando algo que satisfarias nossos desejos? (REALE, 2002) Não satisfaz mais a resposta de que a lei é composta de ditames divinos, ou a ordem do cosmos, ou mesmo na própria "condição humana". É necessário um novo fundamento, uma teoria da justiça. Estas questôes estão vinculadas diretamente ao próprio conceito de Direito, nos levando a questionar indiretamente sua própria essência.

O Direito e a lei refletem, antes de mais nada, a ideia de que alguns comportamentos humanos são obrigatórios (HART, 2012). A lei representa normas coercitivas de comportamento, vinculantes na esfera social, impondo açóes e atitudes não mais opcionais. Esta coercibilidade é equivalente a um assaltante que ordena a vítima que lhe entregue a carteira. Esta visão reducionista, embora representativa do conceito de ação obrigatória sobre comando coercitivo, fica aquém da real dimensão do direito e da lei. As normas legais vão além, não apenas impondo obrigaçôes, mas em certas áreas de contida limitando às opçóes, subtraindo a livre opçáo, algo semelhante a normas morais e, embora este segundo conceito seja importante, náo impede o primeiro. No sistema jurídico, ambas as dimensóes estáo presentes, da ameaça e da limitação de comportamentos. Unindo estes dois campos, estas duas dimensôes, tem-se a ideia de justiça. Justiça de acordo com a lei, e a justiça das leis.

Apesar de apresentarem uma certa semelhança, não se deve confundir justiça com moral. Apesar de ambas precederem o direito, justiça é um conceito ligado ao direito e este e a moral, não obstante com raízes em comum, são coisas diferentes. Justiça está ligada à ideia de Estado, como aponta São Agostinho, um Estado sem justiça não passa de um bando de ladróes. Já a moral está mais próxima da esfera individual, embora seja possível uma moral coletiva ou até mesmo uma moralidade política ${ }^{1}$. Contrário sensu, não se deve confundir a justiça com a fundamentação da obrigatoriedade da lei, mas apenas sua finalidade. O fundamento de validade é a legitimidade. Assim, uma lei, mesmo que injusta, deve ser obedecida, rompendo com as ideias de lex iniusta non est lex, pois aceitar tal preceito seria aceitar uma fundamentação moral do direito. Leis muitas vezes carecem de virtudes. Basta dizer que moral e justiça trabalham com lógicas e critérios diferentes. Justiça pode ser

\footnotetext{
${ }^{1}$ Conforme as liçóes de Dworkin, a moralidade política é a base de fundamentação para a decisão jurídica correta.
} 
considerada como uma moralidade específica da ideia de Direito, com conceitos de justo-injusto, enquanto a moral em geral é vista em um contexto subjetivo interpessoal, com conceitos de bom-mau ou certo-errado. Tal ideia pode ser melhor exemplificada com a ideia de uma lei que obrigue os pais e encaminhar os filhos para a escola como uma lei boa, e uma lei que implemente a censura como má, ao passo que uma lei que implemente o imposto sobre grandes fortunas seria justa, e uma lei que discrimine uma parcela da população por razóes de raça ou gênero seria injusta (HART, 2012). A justiça, assim assume uma forma mais específica do que a moral, podendo muitas vezes, inclusive, se confundir com a palavra "equitativo" ou "imparcial".

O princípio geral latente nessas diversas aplicações da ideia de justiça é que os indivíduos fazem jus, uns em relação aos outros, a uma certa posição relativa de igualdade ou desigualdade. Isto é algo a ser respeitado nas vicissitudes da vida social, quando encargos ou benefícios têm de ser distribuídos; é, também algo a ser restaurado, se tiver sido perturbado (HART, 2012, p. 206).

Para o Direito, a questão da justiça é ainda mais relevante em sua aplicação, pois se tratando de igualdades ou diferenças, estas sempre existiram em abundância, e é necessário, portanto, eleger quais diferenças são relevantes. A imparcialidade é um dos principais critérios, sob esta óptica, para a possibilidade de uma decisão justa, algo que muitas vezes vai, inclusive, em contramão da moral geral. É necessário que a aplicaçáo seja feita da mesma forma a todos, sem nenhum preconceito, interesse ou capricho (HART, 2012). Pressupondo-se, é claro, que a lei sendo aplicada seja, originalmente, justa e legítima. Tanto a legitimidade, precedente, como a justiça, consequente, deverão estar presentes tanto na lei como em sua aplicação.

As leis consideradas justas são aquelas que possuem uma virtude específica de justiça. Este valor não é apenas diferente de outros valores, como também as exigências da justiça podem entrar em conflito com estes outros valores. Por exemplo, um criminoso habitual pode ter sua pena majorada em relaçáo a crimes semelhantes como uma advertência, sacrificando a equidade em prol de uma segurança ou bemestar social. Pode também a lei obrigar o culpado a indenizar aquele a quem prejudicou, mesmo que não se julgasse isso moralmente obrigatório, como nos casos de responsabilidade objetiva no direito civil, independente de dolo ou culpa. A justiça é sempre, e no mínimo, "uma condição necessária a ser satisfeita em qualquer escolha legislativa que se pretenda orientada pelo bem comum” (HART, 2012, p. 216 e 217). 
Porém, a justiça está vinculada com a finalidade, com os objetivos das leis e do Direito. Tal importância não pode ser minimizada, porém não responde à questão de “qual lei?" e "qual direito?". Para isso, discute-se a legitimidade.

\section{Legitimidade}

Legitimidade é, essencialmente, a resposta para a pergunta sobre a razáo de uma lei ser válida. Por que um tribunal produz decisóes vinculantes e por que devemos obedecer à lei. Esta questão está presente desde os primórdios do Direito e desde o início da cultura, sendo feitas pelo homem comum e pelos filósofos, políticos, etc. (REALE, 2002). Muitas respostas foram propostas e, mesmo nos tempos contemporâneos, muitas estáo presentes.

Saindo da antiguidade e da origem divina ou natural da lei e da ordem social, com a advento do iluminismo se fizeram necessárias encontrar respostas humanas para esta questáo. Durante muito tempo o fundamento estava em manifestaçôes comuns do ser humano, como a história, as tradições, a cultura e a moral. Com o advento de Hans Kelsen e sua teoria pura do direito, entretanto, se torna necessário buscar no próprio direito a fonte de sua legitimidade. Em face de tal questão, Kelsen propóe o conceito da norma fundamental (KELSEN, 1998) como fundamento de validade da ordem normativa. Toda validade de uma norma decorre necessariamente de outra norma, dentro de critérios de hierarquia, e, portanto, a ordem normativa também deve ter sua validade baseada em uma norma. Esta norma hipotética, não posta por nenhuma autoridade, é a norma fundamental, um pressuposto mental científico.

A norma fundamental está, para Kelsen, situada no topo de uma pirâmide, com das demais normas abaixo. Especificamente, imediatamente abaixo da norma fundamental se localiza o fundamento da ordem jurídica posta de um Estado, a constituição. Esta constituição, tendo como fundamento de validade, eficácia e legitimidade na norma fundamental, seria por sua vez o fundamento de validade, eficácia e legitimidade das normas gerais.

Se se pergunta pelo fundamento de validade de uma norma pertencente a uma determinada ordem jurídica, a resposta apenas pode consistir na recondução à norma fundamental desta ordem jurídica, quer dizer: na afirmaçáo de que esta norma foi produzida de acordo com a norma fundamental (KELSEN, 1998, p. 222). 
A teoria de Kelsen, porém, foi criticada por não possuir existência empírica. Alf Ross criticou a ideia de norma fundamental, "ao fazer da validade uma relação internormativa (a validade de uma norma deriva da validade de outra), Kelsen se impediu, desde o começo, de lidar com o cerne do problema da vigência do direito: a relação entre o conteúdo ideal normativo e a realidade social" (ROSS, 2000, p. 97).

$\mathrm{Na}$ década de 1960, Herbert Lionel Adolphus Hart propôs uma alternativa a visão normativista de Kelsen, bem como ao realismo de Ross. Para ele, todo sistema jurídico é um conjunto de regras sociais, até mesmo os mais antigos. Mas o sistema jurídico moderno possui diferentes tipos de regras, primária e secundárias, sendo as secundárias por sua vez regras de modificação, de julgamento e de reconhecimento (HART, 2012).

Para a doutrina da soberania, em toda sociedade humana em que exista o direito, existe uma última instância, um soberano. Tanto em uma democracia como em uma monarquia absoluta, há a relaçáo entre os súditos e o soberano, sendo que os primeiros prestam obediência habitual ao último, que não obedece habitualmente a ninguém. Se referindo a esta doutrina, Hart destaca dois pontos importantes (HART, 2012): o hábito de obediência e a posição ocupada pelo soberano, acima da lei, cujo status de legislador supremo, em tal doutrina, é necessário para a existência do direito.

Hart indica, entretanto, que nem sempre a obediência a um soberano decorre do hábito. Certas leis, de fato, podem ser obedecidas como hábito adquirido, como dirigir de um único lado da estrada. Mas leis que contrariam inclinaçôes fortes, como a exigência do pagamento de impostos, não terá o caráter enraizado de um hábito, mas, sob pena de puniçóes, serão obedecidas. A obediência, em um modelo de soberania, é uma relação pessoal entre cada súdito e o soberano, cada um fazendo regularmente o que aquele lhe ordena. Cada um obedece habitualmente ao soberano, mesmo que algumas leis não sejam obedecidas por hábito. Este modelo seria demasiadamente simples para ter existido, porém possui traços importantes de uma sociedade regida pelo direito, até mesmo uma unidade que poderia ser chamada de "Estado", derivada do fato de todos obedecerem à mesma pessoa.

Imagina-se, agora, que, na sociedade baseado no modelo da soberania, o soberano venha a falecer, substituído por ser herdeiro. O mero fato de ter havido um hábito de obediência generalizada ao predecessor não garante, ou sequer torna provável, a obediência ao ser herdeiro. Não existe ainda o hábito estabelecido de obediência ao herdeiro, salvo uma última ordem do antigo soberano, antes de seu falecimento. 
Assim, é característico de um sistema jurídico, mesmo numa monarquia absoluta, assegurar a continuidade ininterrupta do poder de criar o direito, por meio de normas que promovem a transição entre um legislador e outro; essas normas regulam a sucessão antecipadamente, nomeando ou especificando em termos gerais as qualificaçóes do legislador e a forma de defini-lo (HART, 2012. p. 72).

A mera ideia de obediência habitual não é, portanto, suficiente, e fracassa duplamente. Em primeiro lugar, o hábito de obediência não pode ser outorgado, com um legislador o atribuindo ao seu sucessor. Em segundo, a obediência habitual a um legislador não torna provável ou pressupóe que as ordens de um novo legislador seráo obedecias. Para tal, é necessária a aceitação de uma norma segundo a qual o novo legislador terá o direito à sucessão.

Enquanto para a existência de um hábito basta uma convergência de comportamentos de um grupo, e os afastamentos de tal conduta podendo nem mesmo serem sujeitos à crítica, no caso de normas os desvios são sujeitos não apenas à crítica, mas também à censura. Um hábito generalizado é apenas a constatação de um fato, enquanto uma norma depende de que, pelo menos, algumas pessoas encarem o comportamento em questão como um padrão geral a ser seguido pelo grupo como um todo. Para Hart (2012, p. 75), “uma norma social tem um aspecto 'interno', além do aspecto externo que compartilha com um hábito social e que consiste no comportamento costumeiro e uniforme que um observador poderia registrar".

Observa-se, neste ponto, dois tipos de normas. Uma direcionada a condutas específicas, permitidas ou proibidas. São as normas que criam obrigaçôes. Estas são as regras essenciais do direito, notadamente a lei penal (que proíbe ou impóe determinados atos sob ameaça de punição), a mais semelhante as ordens apoiadas por ameaças. Além deste tipo, outro tipo também é observado que, entre outras coisas, outorgam poderes jurídicos para exarar decisões ou legislar. São normas que regulam as primeiras e organizam o sistema jurídico (HART, 2012). A obediência habitual a um soberano, ainda, não pode explicar a continuidade da autoridade legislativa, continuidade esta que é característica dos sistemas jurídicos modernos. Tal fato é de destacado valor para a presente análise, estando intrinsecamente ligado ao conceito de legitimidade pois, para ser vinculante, a produção da autoridade legislativa continuada deve ser considerada legítima. Um soberano que, em seu leito de morte, furte-se de dar uma ordem expressa para transferência da autoridade ao seu sucessor, não pode ser tratado como se emanando uma ordem tácita. Isso não pode ser 
aceitado, sendo apenas aplicável a um modelo extremamente simples e não possível em um sistema jurídico complexo. Um novo conceito se faz necessário. Os conceitos antigos, como ideias de ordens, obediência, hábitos e ameaças, não são capazes e não incluem a ideia de uma norma, "sem a qual não teremos a esperança de elucidar nem sequer as formas mais elementares do direito" (HART, 2012, p. 105). Seja estas normas primárias, que exigem a prática ou abstenção de condutas, impondo deveres, sejam elas secundárias, outorgando poderes. Estas normas secundárias são então dividias em três tipo: de modificação, de julgamento e de reconhecimento.

Normas de modificação (HART, 2012) são aquelas que se apresentam como solução para o caráter estático do regime de normas primárias. Em sua forma mais elementar, autoriza uma pessoa ou grupo de pessoas a introduzir novas normas primárias, e a eliminar normas antigas. É em função destas normas que se pode entender a ideia de promulgação e revogação de leis. Estas normas incluem não apenas a forma (procedimentos) e os poderes (limites), limitados ou ilimitados, como também indicam as pessoas autorizadas, ou melhor, encarregadas de legislar. As normas de modificação não apenas afetam a função normativa privada, em situação que criam ou modificam direitos e obrigaçóes: testamentos, contratos, transferências de propriedade, etc. Neste último caso, ocorre um encontro entre as normas de modificação com as normas primárias pois, sem dúvida, a atividade normativa da esfera privada também deve respeitar os limites das normas primárias do Estado.

Suplementando o regime simples de normas primárias, visando remediar a ineficiência de sua pressão social difusa, estão as normas que capacitam alguns indivíduos a solucionar o problema de saber se foi violada uma norma primária, em um caso específico. Estas são as normas de julgamento, normas secundárias que outorgam o poder de formular estas determinaçóes. Como outras normas secundárias, estas se situam em um nível diferente das primárias e, “embora possam ser reforçadas por normas adicionais que imponham aos juízes o dever de julgar, elas não impóem deveres, mas conferem poderes judicias e um status especial às declaraçôes judiciais sobre o não-cumprimento das obrigaçóes” (HART, 2012, p. 125). As normas de julgamento definem conceitos jurídicos importantes: o conceito de juiz ou tribunal, jurisdição e julgamento. Estas normas possuem mais uma outra ligaçáo ao conceito de legitimidade, pois se os tribunais tiverem o poder de determinar peremptoriamente que uma norma foi desrespeitada, tal decisão não poderá deixar de ser considerada uma determinação autorizada sobre a natureza das próprias normas. Desta forma a norma que confere jurisdição também está dotada de legitimidade, concedendo-a, e tais julgamentos se tornam "fonte" do direito. 
Por último, o terceiro tipo de norma secundária são as regras de reconhecimento, estando estas no cerne da questão de legitimidade para Hart. Estas determinam os critérios indicativos de quais regras podem pertencer ao sistema, sendo um fato social aceito na prática como fundamento de validade das outras regras e, por isso, de certa forma semelhante à norma fundamental de Kelsen, porém com distinçôes importantes.

Dada a já mencionada incerteza presente em um sistema de normas, sobre quais normas primárias valem e quais devem ter seguidas, a solução mais simples é a introdução de normas de reconhecimento.

Essa norma específica as características que, se estiverem presentes numa determinada norma, serão consideradas como indicação conclusiva de que se trata de uma norma do grupo, a ser apoiada pela pressão social que este exerce. A existência dessa norma de reconhecimento pode assumir qualquer uma dentre uma imensa variedade de formas, simples ou complexas (HART, 2012, p. 122).

Normas de reconhecimento podem inclusive ser orais ou implícitas, desde que sejam aceitas como tal e estão intrinsecamente ligadas ao conceito de validade, eficácia e legitimidade. Suas formas, incluindo, entre as inúmeras possíveis, a referência a um texto autorizado, a um ato legislativo, à prática consuetudinária, a declaraçóes gerais de pessoas específicas ou até mesmo a decisóes judiciais anteriores sobre casos específicos. Em um sistema de monarquia absolutista, o critério de verificação será, para fins de identificar o Direito, a identificação de que a norma se originou no monarca. Se este critério, esta norma de reconhecimento, está vinculada a figura do monarca, e não a pessoa, o problema da autoridade do seu sucessor se encontra resolvido, uma vez que as decisôes do novo monarca iráo se enquadrar nos critérios verificados, não sendo necessário um comando do anterior, seja explícito ou implícito.

Em um sistema jurídico mais complexo, como nos modernos, as regras de reconhecimento serão também necessariamente mais complexas. Existem várias "fontes" do direito, e os critérios para identificação da norma jurídica também são múltiplos e geralmente incluem uma constituição, frequentemente escrita, a legislação e os precedentes judiciais, estando, na maioria dos casos, presentes mecanismo de solução de possíveis conflitos através de ordens de subordinação hierárquicas. 
Dizer que determinada regra é válida equivale a reconhecer que esta satisfaz a todos os critérios propostos pela norma de reconhecimento e é, portanto, uma norma do sistema. $\mathrm{Na}$ verdade, pode-se simplesmente dizer que a afirmação de que certa norma é válida significa que tal norma satisfaz a todos os critérios oferecidos pela norma de reconhecimento (HART, 2012, p. 133).

Tais normas podem, como afirmado, assumir diversas formas, e são caracterizadas e identificadas por sua aceitação. Uma vez que as regras de reconhecimento são aceitas, tal critério de validade e legitimidade indica que as normas primárias por ela validadas devem ser seguidas. Em alguns casos, pode até a norma de reconhecimento não estar explicitamente declarada (HART, 2012), mas sua existência fica demonstrada pela forma como se identificam normas específicas no plano fático, por juízes, autoridades, particulares e advogados. Por exemplo, tribunais são válidos pois existem e são respeitados. Se não o fossem, não existiriam.

Cabe, ainda diferenciar as regras de reconhecimento da norma fundamental de Kelsen, uma vez que ambas são fundamentos normativos de legitimidade do sistema jurídico. A primeira diferença está no fato da norma fundamental ser hipotética, enquanto a regra de reconhecimento é fática. Tal existência empírica irá satisfazer tanto as expectativas normativas científicas como as realistas, como da crítica de Alf Ross. Cabem ainda outras diferenças importantes. 
Quadro 1 - Regras de Reconhecimento vs. Norma Fundamental

\begin{tabular}{|c|c|}
\hline Regra de Reconhecimento & Norma Fundamental \\
\hline Fato social & Hipótese \\
\hline Usado & Pensada \\
\hline $\mathrm{Na}$ prática jurídica & Pelas teorias jurídicas \\
\hline $\begin{array}{l}\text { Para reconhecer as regras que pertencem ao } \\
\text { sistema }\end{array}$ & Para afirmar a validade da Constituição \\
\hline Não depende de coerção para sua validade & É baseada na coerção \\
\hline Sua existência é uma questão de fato & É ficcionalmente pressuposta \\
\hline $\begin{array}{l}\text { Sua função é fornecer um critério de } \\
\text { reconhecimento para a identificação de regras }\end{array}$ & $\begin{array}{l}\text { Sua função é validar todas as normas de um } \\
\text { sistema }\end{array}$ \\
\hline Pode incluir vários critérios de validade & Só existe uma norma fundamental \\
\hline $\begin{array}{l}\text { Fornece validade às regras dentro de um } \\
\text { ordenamento jurídico ao permitir que oficiais } \\
\text { reconheçam outras normas secundárias e } \\
\text { primárias }\end{array}$ & $\begin{array}{l}\text { Fornece validade a todo ordenamento jurídico, e } \\
\text { também é fonte de todas as outras normas }\end{array}$ \\
\hline Fornece unidade ao ordenamento jurídico & $\begin{array}{l}\text { Permite que o aplicador do direito interprete a } \\
\text { validade das normas em um campo de } \\
\text { significação náo-contraditório }\end{array}$ \\
\hline $\begin{array}{l}\text { Sua validade (que náo possui } \text { qualquer } \\
\text { importância em sua teoria) não pode ser } \\
\text { demonstrada; ela simplesmente existe }\end{array}$ & $\begin{array}{l}\text { É pressuposta em termos de eficácia; dessa forma, } \\
\text { precisa ser válida }\end{array}$ \\
\hline $\begin{array}{l}\text { Não há conexáo necessária entre a validade e } \\
\text { eficácia de uma regra (salvo se a regra de } \\
\text { reconhecimento contiver essa previsão) }\end{array}$ & $\begin{array}{l}\text { A sua escolha não é arbitrária e depende } \\
\text { necessariamente da eficácia }\end{array}$ \\
\hline
\end{tabular}

Fonte: Elaborado pelos autores a partir de Batalha (2012) e Wacks (2012).

Outra diferença notadamente importante é o fato da norma fundamental ser única, enquanto as regras de reconhecimento são várias. Através destas, para Hart, se define a legitimidade de uma norma.

\section{Derrotabilidade}

Da mesma forma que um sistema jurídico possuirá regras de reconhecimento que, através de critérios de validade, conferem legitimidade e eficácia a normas primárias, também existem regras que retiram tal eficácia e estas, da mesma forma, estão ligadas ao conceito de legitimidade. Se a legitimidade implica em quando uma norma deve ser obedecida e, em sua ausência, quando não deve ser obedecida, está também pode, de maneira positiva, estabelecer limites à eficácia. 
Conceitos e normas jurídicas muitas vezes são necessariamente vagos ou excessivamente abrangentes. Esta questão inclui as indeterminaçôes já identificadas por Kelsen, em que "por mais detalhada, por mais pormenorizada que seja a norma superior, a norma inferior sempre apresentará margens de determinação a fazer" (SIMIONI, 2014, p. 193). Mesmo normas determinadas ainda podem possuir critérios de não aplicabilidade externos apreciáveis através da interpretação ${ }^{2}$. Uma acusação feita em uma corte pode ser oposta de suas formas. A primeira é a negativa dos fatos em que se baseia. A segunda forma, por outro lado, ocorre quando náo se negam os fatos, ou mesmo os admitem-se, mas, ainda, expóem-se a existência de alguma outra circunstância que, estando presente, indicam uma exceção, de maneira que a acusação não deve ser bem-sucedida ou, se sucedida, de efeito reduzido (HART, 1948/1949). Tal circunstância não está ligada a elementar da conduta, ou algo que afete o silogismo entre a norma geral e a aplicaçáo específica, onde seria apenas uma questão de interpretação, mas sim uma circunstância externa que, presente, afeta a efetividade da norma.

Um exemplo clássico poderia ser o da legítima defesa, em um caso de homicídio. Enquanto a norma penal prevê o tipo "matar alguém", a interpretação e a argumentaçáo poderiam ser utilizadas para se verificar a adequaçáo do tipo ao fato. A vítima estava viva antes da conduta? Era uma pessoa (alguém)? A conduta foi realizada pelo suposto autor? Existe um nexo causal entre a conduta e o resultado? Todos estes critérios, perguntas e fatos estáo ligados a aplicabilidade da norma ao caso concreto ou, segundo Kelsen, da definiçáo da moldura para a aplicaçáo da norma. Porém, é possível que o autor confirme o fato e admita sua autoria, situação onde a aplicabilidade da norma seria clara e perfeita. E, tendo confirmado os fatos, venha entâo a alegar um fato novo (uma excludente, no ordenamento pátrio) que, sem afetar o fato ou o tipo, imponha uma cláusula restritiva de eficácia à norma. No caso, a legítima defesa.

Esta legítima defesa não é elementar da norma, mas é, por sua vez, uma outra norma, positivada em conjunto ("salvo se") ou separado (geral) que limita a eficácia da norma primária. Tal norma se faz necessária pois, na definição da norma não é possível incluir todas as hipóteses positivas de concretização da mesma. Não é possível incluir no tipo penal de homicídio absolutamente todas as circunstâncias em que esta

\footnotetext{
${ }^{2}$ Náo obstante o fato de, para Kelsen, a interpretação fazer parte do processo de criaçáo da norma, Hart trabalha com a própria interpretação, quando feita de acordo com as regras de reconhecimento, como uma norma em si, e o produto desta pode ser sujeito do processo de derrotabilidade.
} 
deve ser aplicada. Deve-se entáo incluir a norma como regra geral, e novas regras limitando ou excluindo a eficácia da regra primária de caráter geral.

Tais regras limitadoras não são exclusivas do direito penal. No direito civil, quando se estudam contratos, observam-se diversos requisitos positivos para a existência dos mesmos, a presença de partes, acordo de vontade, etc. Porém, os requisitos positivos não são suficientes, pois não podem incluir todas as situaçôes possíveis que podem vir a derrotar a norma, critérios condicionais ou negativos, como a que estabelece não poder ser objeto de contrato a herança de pessoa viva, ou o fato da proposta obrigar o proponente se o contrário náo resultar dos termos desta. Temse assim regras de derrotabilidade sendo apresentadas em separado e em conjunto, uma vez que a aplicação das palavras "condicionais" ou "negativas", segundo Hart, trazem implicações errôneas (HART, 1948/1949, p. 175). O contrato, enquanto norma, é um conceito derrotável.

Normas de derrotabilidade podem, ainda, ser gerais ou específicas. Como no caso da obrigação do proponente, a derrotabilidade é específica. No caso da incapacidade civil de menores, tem-se uma regra geral de derrotabilidade, aplicável a todo o ordenamento a que se refere. A inimputabilidade penal se aplica a todo o direito penal, assim como a incapacidade civil se aplica a todo o direito civil.

Mesmo regras de derrotabilidade podem ser derrotadas. No exemplo da incapacidade civil, um incapaz náo responde, para fins de responsabilidade penal, com seu patrimônio, algo que é característico da derrotabilidade da norma da obrigação de indenizar. Porém, mesmo o patrimônio do menor pode ser alcançado, se aquele que tem a obrigação de indenizar (por exemplo, seus pais) não o puderem, uma derrotabilidade da regra de derrotabilidade. E esta também é derrotável pelo princípio da proteçâo total ao menor, que irá impedir que o patrimônio do menor seja dilapidado de forma a náo garantir o seu sustento. Toda esta cadeia de regras, partindo de uma regra primária e passando por várias regras secundárias (essencialmente regras de julgamento) com diversos critérios de limitação ou restrição da eficácia da regra primária original, ou seja, derrotabilidade da mesma, se faz necessário de maneira a se ter um maior grau de especificidade da norma, algo impossível de ser feito em sua gênese e na sua redaçáo. A derrotabilidade passa a ser tão importante para a correta aplicabilidade das regras, limitando-as, como um "etc" seria para ampliar o seu alcance. Por esta ótima, até mesmo princípios constitucionais, uma conquista pós-positivista, poderiam muitas vezes ser 
considerados critérios de derrotabilidade. A função social representa uma derrotabilidade do direito de propriedade.

Tais regras são possíveis no ordenamento pátrio, tendo-se observado o caso paradigmático em que o STF decidiu pela derrotabilidade da norma ao permitir o caso de aborto de feto anencefálico (BRASIL, ADPF 54/DF, 2012), superando, ou derrotando, o crime de aborto para o caso específico, que continua a existir com sua redação original no Código Penal. Observa-se que esta não foi uma decisão interpretativa, mas sim um critério limitador da eficiência da norma, uma exceção a aplicabilidade da mesma. Então, um caso de derrotabilidade.

Enquanto para Hans Kelsen de que a norma é o resultado a interpretação do texto diante do caso concreto, caso em que náo seria a norma a ser derrotada, mas sim o enunciado normativo (CUNHA JÚNIOR, 2015), para Hart o processo interpretativo da norma por um tribunal, uma vez dotado de validade por critérios estabelecidos em uma regra de reconhecimento, e, portanto, legítimo, tem função normativa, o que justifica se afirmar que a própria norma é derrotada.

Pode-se, então, afirmar que embora o critério de legitimidade das normas está vinculado diretamente às regras de reconhecimento, a efetividade para aplicaçáo das mesmas está vinculada tanto à própria norma primária, quanto as hipóteses de derrotabilidade da mesma. E uma vez que tanto as regras de derrotabilidade com a própria aplicação das mesmas, através dos tribunais, para serem legítimas, dependem das regras de reconhecimento, estas também terão relação com a legitimidade do ordenamento jurídico.

\section{Considerações finais}

Existem diversas, se não inúmeras, hipóteses e teorias para responder as questôes da legitimidade. Isto, ao mesmo tempo, indica a importância e a complexidade da própria questáo, e da busca por sua resposta. Mesmo náo se alcançando uma resposta definitiva, a busca em si própria auxilia no avanço da democracia e da sociedade.

Herbert Lionel Adolphus Hart não foi o primeiro e nem o último a oferecer uma resposta para a legitimidade. O que Hart oferece de diferente é uma visão fundada tanto em teoria filosófica do Direito, alicerceada em um profundo senso de justiça, como ao mesmo tempo com um viés pragmático: se respeitamos algo, isto é legítimo.

Hart também nos propicia uma metodologia que permite encontrarmos no próprio ordenamento jurídico as respostas para ele próprio, respostas estas que são 
fatos já presentes passíveis de identificação, e não construçôes abstratas. Tem-se, assim, uma resposta, se não ideal, averiguável e fundada na realidade. Mais do que isso, por se basear em critérios de validade, a teoria de Hart indica um meio de unidade para o ordenamento jurídico. Trata-se de um processo de reconhecimento, e não coercitivo.

Por último, Hart propóe que, se existem critérios de eficácia para as regras, é possível a existência de critérios que retirem a eficácia de regras, limitando ou excluindo as mesmas. Esta característica, é chamada por ele de derrotabilidade. Novamente, é possível a identificação destas regras de derrotabilidade no próprio ordenamento, como no caso de excludente de ilicitude da legítima defesa. Ainda, demonstra como as próprias regras de derrotabilidade podem ser derrotadas.

Hart apresenta uma visão ampla do Direito e das leis, alcançando desde os alicerces da justiça até critérios de aplicação passando, obrigatoriamente, pela própria questão da legitimidade. E, se sua teoria não é perfeita ou definitiva, em muito contribui para um melhor entendimento da questáo central deste artigo: a legitimidade.

Rafael Lazzarotto Simioni é Pós-Doutor em Filosofia e Teoria do Direito, pela Faculdade de Direito da Universidade de Coimbra e Doutor em Direito Público, pela Universidade do Vale do Rio dos Sinos. É Professor da Faculdade de Direito do Sul de Minas (FDSM) e da Universidade do Vale do Sapucaí-Univás. Vice-coordenador e Professor do programa de mestrado da FDSM. E-mail: simioni2010@gmail.com.

Rodrigo Pedroso Barbosa é Graduando em Direito, pela FDSm. Membro dos grupos de pesquisa "Margens do Direito" e "Razão Crítica e Justiça Penal", certificados pela FDSM e inseridos no Diretório de Grupos de Pesquisa do CNPq. E-mail: rodrigob@fdsm.edu.br.

\section{Referências}

BATALHA, Carlos Eduardo. Filosofia do Direito. São Paulo: Saraiva, 2012. 
BRASIL. Supremo Tribunal Federal. Arguição de Descumprimento de Preceito Fundamental 54.12 abr. 2012. Feto anencéfalo - interrupção da gravidez - mulher - liberdade sexual e reprodutiva - saúde dignidade -autodeterminação - direitos fundamentais - crime -inexistência. Diário da Justiça Eletrônico. Brasília, DF: STF. n. 80. p. 19-20. 30 abr. 2013.

CANOTILHO, Gomes. Direito Constitucional e Teoria da Constituição. 7 ed. Coimbra, Portugal: Almedina, 2003.

CUNHA JÚNIOR, Dirley. O que é derrotabilidade das normas jurídicas? Disponível em $<$ http://dirleydacunhajunior.jusbrasil.com.br/artigos/207200076/o-que-e-derrotabilidade-dasnormas-juridicas>. Acesso em 14 dez. 2015.

HART. Herbert Lionel Adolphus. O Conceito do Direito. 1 ed. São Paulo: WMF Martins Fontes, 2012.

. The Ascription of Responsibility and Rights. Proceedings of the Aristotelian Society. New Series. v. 49, 1948/1949, p. 171-194. Disponível em <http://www.jstor.org/stable/4544455>. Acesso em 3 set. 2014.

KELSEN, Hans. Teoria Pura do Direito. 6 ed. 5 tiragem. Sáo Paulo: Martins Fontes, 1998.

REALE, Miguel. Liçôes Preliminares de Direito. 27 ed. Sáo Paulo: Saraiva, 2002.

ROSS, Alf. Direito e Justiça. Trad. Edson Bini. Bauru, SP: Edipro, 2000.

SIMIONI, Rafael Lazzaroto. Curso de Hermenêutica Jurídica Contemporânea: do positivismo clássico ao pós-positivismo jurídico. Curitiba: Juruá, 2014.

WACKS, Raymond. Understanding Jurisprudence: An Introduction to Legal Theory. Oxford: OUP Oxford, 2012. 